\title{
DISCURSO DE PARANINFO
}

José Carlos BRUNI ${ }^{1}$

A Osvaldo Cunha Neto

- RESUMO: O presente texto é o discurso de paraninfo pronunciado para os formandos da turma de 2001 da Faculdade de Filosofia e Ciências da Universidade Estadual Paulista, Campus de Marília/SP. Constitui-se em pequena reflexão sobre o momento da formatura, a passagem para a vida profissional e os problemas mais candentes que a vida acadêmica enfrenta hoje no Brasil.

- PALAVRAS-CHAVE: Formatura; rito de passagem; estudante; educação; Universidade; organização; instituição.

Esta ocasião - a formatura da turma de 2001 da Faculdade de Filosofia e Ciências da UNESP, Campus de Marília - é propícia para refletirmos sobre o sentido do evento que estamos comemorando.

Toda cerimônia deste tipo comporta o adeus e as boas-vindas. Adeus ao que, ficando para trás, chegou ao seu término. Boas-vindas àquilo que se espera começar e inaugurar um novo tempo. Os antropólogos cunharam a expressão "rito de passagem" para designar o conjunto de preceitos que devem acompanhar toda mudança de lugar, de estado, de posição social e de idade que a comunidade decide marcar. O momento ritual é

1 Professor do Departamento de Filosofia da FFC/UNESP/Marília. 
solene, palavra que literalmente significa aquilo que acontece apenas uma vez por ano, indicando assim o caráter especial do evento que atinge a vida das pessoas com intensidade suficiente para que não seja facilmente esquecido. Assim, nesta solenidade quer-se, antes de mais nada, simbolizar o término da condição de estudante e o ingresso na vida profissional.

Quais são os personagens deste ritual de passagem? Os estudantes, evidentemente, mas também seus professores, amigos e familiares. Especialmente os membros de sua própria família, que não devem ser vistos apenas como atores coadjuvantes ou secundários, mas, pelo contrário, como protagonistas do drama familiar que envolve todo o tempo da formação do estudante. Digo drama familiar porque neste país a deliberação de proporcionar aos filhos e filhas a assim chamada educação superior acarreta uma série enorme de sacrifícios de ordem material e espiritual. Um filho ou uma filha na Universidade é motivo de apreensão permanente, vivida com grande intensidade pelos pais, o que muitas vezes é mal compreendido pelos filhos. A atitude de proteção ante perigos cuja natureza a experiência indica com clareza pode aparecer aos olhos dos filhos como absurda ou como puro controle repressivo. Isto, por sua vez, pode gerar situações dramáticas de conflito em que ambas as partes têm razão: tanto o jovem estudante que descobre fora da família outro mundo, isto é, outros valores, quanto os pais que querem preservar o modo de ser daquilo que tem sido o que sempre foi. Conflito que pode ser bem ou mal resolvido - não é o caso de entrar neste tema neste momento. Deve-se contudo salientar que tanto pais quanto estudantes ao enfrentarem esta dura prova da convivência difícil merecem nosso respeito, pois acabam se transformando em pequenos heróis do cotidiano, cujo sofrimento não pode propriamente ser resgatado.

Os antropólogos alertam também para a importância simbólica de todos os objetos e coisas utilizados no ritual. Ora, como se trata, no nosso caso, da entrega do diploma, pode ser interessante nos determos um pouco sobre o sentido desse tubo vazio que o representa. De modo geral, um objeto de forma cilíndrica - o bastão - é de presença quase obrigatória em muitos rituais de passagem, simbolizando a posse de uma arma mágica, aquela que dá apoio na caminhada do pastor e do peregrino nas pastagens antigas (Chevalier \& Gheerbrant, 1991, p.123 ss.). Apoio para o andar mas também signo de autoridade: o bordão do pastor e o bastão de comando. Na cultura budista, o bastão do monge é apoio para a caminhada e arma de exorcismo: afugenta as influências perniciosas, libera as almas do inferno, amansa os dragões e faz brotarem as fontes: o 
bastão do peregrino e a vara de condão da fada. De modo geral, o bastão do xamã, do peregrino, do amo e do senhor são todos símbolos da montaria invisível, veículo de suas viagens através dos planos e dos mundos. Nas lendas de feitiçarias, o bastão tornou-se a vara de condão graças à qual a fada boa transforma a abóbora em carruagem e a rainha malvada em sapo. O bastão é ainda considerado símbolo do tutor, o mestre indispensável na iniciação. Servir-se do "animal" não significa que o mestre deva bater com ele no discípulo, mas sim que o discípulo avança apoiando-se nele, nos conselhos do mestre. Apoio, defesa, guia, o bastão torna-se cetro, símbolo de soberania, de poder e de comando, tanto na ordem intelectual e espiritual como na hierarquia social e nas hierarquias militar e eclesiástica. Signo de autoridade e de comando, era utilizado na Grécia antiga por aqueles que explicavam a Ilíada e a Odisséia. O bastão relaciona-se igualmente ao fogo e, conseqüentemente, com a fertilidade e a regeneração. Assim como a lança e o pilão, o bastão foi comparado ao órgão sexual masculino, como símbolo fálico. O fogo, como o da centelha, o do relâmpago e o do raio, é fertilizante: faz chover ou brotarem as fontes subterrâneas. Com uma pancada do bastão no rochedo, Moisés descobre uma fonte onde o povo vem matar sua sede. Hermes, segundo a mitologia grega, é quem teria inventado o fogo terrestre, ao esfregar dois bastões de madeira - um de madeira dura, outro de madeira macia. Enfim, a entrega do diploma simboliza o reconhecimento, pela sociedade, do poder superior que seus jovens membros legitimamente conquistaram após uma série interminável de provas e exames, após um longo período de adestramento.

Mas isto não é tudo. Falando sobre a função dos ritos de passagem nas sociedades tribais, assim se expressa o antropólogo Pierre Clastres (1982, p.82):

Os ritos de passagem ... têm por missão comunicar aos jovens um saber sobre sua sociedade, que se prepara para acolhê-los ... Este saber, ... na verdade, não é um saber sobre a sociedade, e portanto um saber exterior a ela. Ele é necessariamente o saber da própria sociedade, saber que lhe é imanente e que, como tal, constitui a própria substância da sociedade, seu Eu substancial, aquilo que ela é nela mesma. No rito [de passagem] os jovens recebem da sociedade, representada pelos ordenadores do ritual, o saber daquilo que a sociedade é, em seu ser, daquilo que a constitui e a institui como tal: o universo de suas regras e de suas normas, o universo éticopolítico de sua lei. O ensino da lei, e em seguida a prescrição da fidelidade a esta lei, na medida em que ela assegura a continuidade, a permanência do ser da sociedade. 
E continua Clastres: "no plano do desenrolar concreto dos momentos do ritual, os ancestrais estão, implícita ou explicitamente, implicados e presentes por necessidade. Não é deles que os jovens se preparam para receber o ensino? Figuras maiores de qualquer rito de iniciação, os ancestrais são o objeto real do culto nos rituais de passagem" (p.83). Assim, os ritos de passagem sinalizam de maneira clara um antes e um depois, o término e um novo início. Isso porém vale para as sociedades tribais, muito diferentes das nossas. Será que essa função temporal clara pode ser constatada nas sociedades modernas em que vivemos?

Ora, é fácil responder que não. Os fatos são evidentes demais para serem negados. Em primeiro lugar, não há uma situação clara na própria Universidade. Não há um saber a ser transmitido ou pelo menos unificado pela mesma inspiração de fundo, ou seja, por uma única filosofia. A Universidade é, hoje, palco de uma luta acirrada entre duas concepções básicas sobre o que seja a educação, seus fins e meios, enfim uma luta encarniçada entre duas concepções em que valores opostos são defendidos com igual ímpeto. Numa primeira posição estão agrupados aqueles que defendem a função essencialmente formadora e crítica da Universidade contra aqueles que, numa segunda posição, defendem a função essencialmente técnica e profissionalizante da Universidade. Se no nível da teoria essas concepções podem ser harmonizadas, na prática elas acabam por se tornar antagônicas. A primeira vê a Universidade como um espaço eminentemente instaurador, inventor e criador da cultura, da ciência e do saber, a vê portanto como instituição, enquanto a segunda posição como meio eficaz da aplicação do saber e da cultura e que deve tomar a forma de uma organização (Cf. Chauí, 2001, p.175 ss.). Eis como se expressa a respeito o Professor Franklin Leopoldo e Silva (1999, p.41):

(a eficácia operacional) tende a destituir a instituição (regulação dos meios pelos fins) porque a atualidade vê a eficácia organizacional como um fim em si mesma e como a única finalidade. Na medida em que legitimidade e utilidade imediata se sobrepõem, e os critérios utilitaristas se transformam em normas, deixa de ter sentido qualquer instituição que se governe pela mediação crítica e pela recusa da normatividade extrínseca ... Como não é possível o exercício imediato da autoridade numa sociedade em que prevaleça o espaço público, a universidade enquanto instituição torna-se um estorvo e um aparato arcaico em qualquer sistema de poder que pretenda substituir a mediação política pela imposição tecnocrática da autoridade, exercício direto de um poder que é respaldado na razão técnica e não no 
diálogo e na persuasão política. O caráter imediato deste poder não pode conviver com a institucionalização da crítica e do debate, já que substituiu as mediações propriamente políticas por instâncias autoritárias de formação e controle de opinião.

Entendida como instituição, a Universidade se define como crítica, isto é, como lugar de permanente retomada e reavaliação de seus fundamentos e seus pressupostos, o que implica a liberdade perante o já estabelecido e estímulo constante à criação de novas perspectivas: a invenção e o novo requerem para si um tempo próprio. Já a Universidade-organização inspira-se no modelo empresarial de gestão administrativa da produção industrial, agrícola e financeira. Prevalece aí a velha idéia de que tempo é dinheiro, isto é, de que todas as atividades estão ordenadas de forma a produzir no menor tempo possível o maior número possível de "produtos". Tudo o que não tiver uma relação visível com esta finalidade é considerado "improdutivo" e supérfluo. Deve-se acentuar que esta mentalidade é inteiramente externa à Universidade. Sua origem está justamente no campo da "economia", mas desde já há alguns séculos vem tomando de assalto toda a sociedade. Recentemente, sob a forma do neoliberalismo e da globalização, foi-se criando um novo ideal de homem: aquele em que este se vê inteiramente como mercadoria. Tomemos o livro de William Bridges, Um mundo sem empregos, que se apresenta como um manual de sobrevivência ao se ter de enfrentar a crise da sociedade atual, provocada pelo desaparecimento do trabalho e do emprego. "Tudo é um mercado" é o título do capítulo 3, idéia que impregna o livro como um todo. O ponto de partida é o preceito: "você precisa ver a si mesmo como se fosse um negócio" (Bridges, 1995, p.111). "Aprenda a encarar toda potencial situação de trabalho, tanto dentro como fora de uma organização, como um mercado" (p.68). Você não deve pensar em pagamento pelo trabalho, "mas como uma forma de troca do que você tem e outra pessoa quer por aquilo que a outra pessoa tem e você quer. Esse tipo de troca é como a natureza funciona: os simbiontes o fazem com seu ambiente, cubos de gelo fazem com o copo d'água que os cerca, as águas do planeta e o céu fazem, e você fará quando transformar a si mesmo num negócio" (p.120). A força de trabalho sempre foi mercadoria no capitalismo; a novidade agora é sua decomposição em unidades mínimas, em que cada uma deve ser tão produtiva como antigamente, quando existia apenas como um corpo. Agora, cada talento, cada capacidade, cada habilidade, cada conhecimento é visto como uma mercadoria singular, devendo o indivíduo administrar a circulação do conjunto delas da forma a mais lucrativa possível. Cada um deve gerenciar o conjunto 
de suas mercadorias, isto é, a totalidade de sua pessoa, como uma soma de itens que podem ser vendidos num mercado cujas demandas exigem minuciosa e precisa identificação. Em suma, neste mundo em que as pessoas se definem exclusivamente como clientes ou fregueses, disputando barbaramente a venda de seus produtos, se requer como condição absoluta a sua mais íntima transformação em mercadoria, ou antes, em um conjunto de mercadorias, cada "talento" com seu preço próprio para cada mercado determinado. É este o ideal de humanidade que se pode inferir dos preceitos para "um mundo sem empregos", tão cinicamente retratado por William Bridges. O lamentável é ver parte da Universidade comprometida com esse tipo de formação que exige a transformação integral do homem em mercadoria.

Mas é preciso lembrar que esta situação de combate entre cultura e anticultura é bem mais antiga do que as recentes lutas no interior da Universidade fazem supor. Já um velho filósofo do século XIX, Friedrich Nietzsche, diagnosticava com surpreendente precisão os temas centrais de toda esta problemática, ou seja, a relação da cultura com o mercado e o Estado. É sintomático o modo como Nietzsche inicia suas conferências Sobre o futuro dos nossos estabelecimentos de ensino (1988, p.648): “O leitor de quem espero alguma coisa deve ter três qualidades: deve ser calmo e ler sem pressa; não deve se interpor - ele e sua 'cultura'; enfim não deve esperar por um quadro final de resultados". Nietzsche aponta assim para um aspecto essencial da cultura moderna: a ausência de condições para a instituição de um tempo suficientemente amplo, livre e elástico, pressuposto real da verdadeira formação, da verdadeira cultura. Só por aí se vê o enorme potencial crítico dessa filosofia que não se cansa de apontar as injunções modernas que aceleram até a loucura o ritmo de vida das pessoas, num afã insano de produzir, produzir cada vez mais, cada vez mais. Esse tempo antinatural, desumano e destrutivo, incompatível com o tempo da criação, da cultura, da ciência e da arte, é que é preciso denunciar e ao mesmo tempo pesquisar sua gênese.

E para encerrar, gostaria de relembrar alguns versos de Carlos Drummond de Andrade, em A rosa do povo (1959, p.191), o poema intitulado Idade madura. Ao invés de propor um caminho a seguir no futuro, o poeta espera algumas fidelidades daqueles que, tendo chegado ao limiar da idade adulta, não poderão jamais deixar de ser jovens:

Já não dirão que estou resignado

e perdi os melhores dias.

Dentro de mim, bem no fundo

há reservas colossais de tempo, 


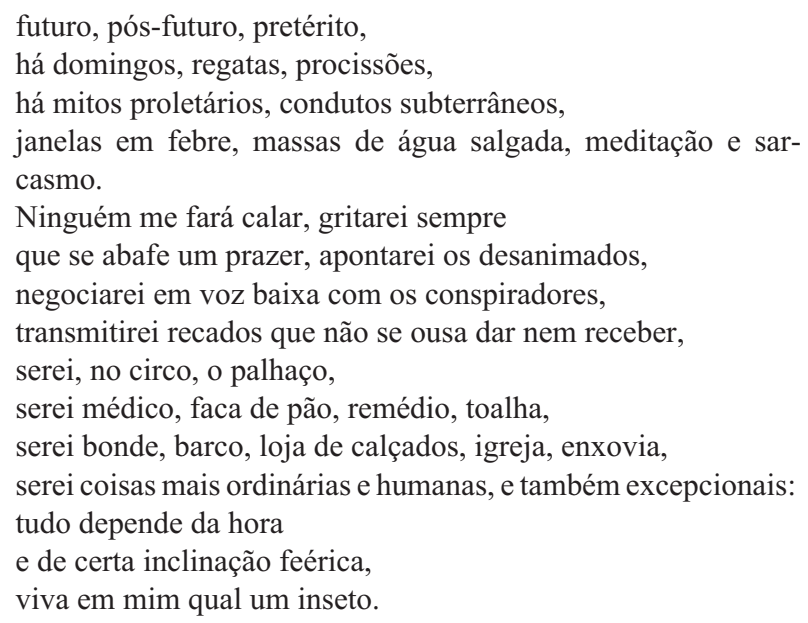

BRUNI, J. C. Guest speaker's address. Trans/Form/Ação (São Paulo), v.25, p.79-85, 2002.

- ABSTRACT: This is the text of the guest speaker's address given on the graduation ceremony of the 2001 class at the Faculdade de Filosofia e Ciencias da Universidade Estadual Paulista at Marilia/São Paulo. It consists in a briefreflection about the moment of graduation, the passage to professional life and the most serious problems of academic life today in Brazil.

- KEYWORDS: Graduation; passage rite; student; education; University; organization; institution.

\section{Referências bibliográficas}

ANDRADE, C. D. Poemas. Rio de Janeiro: José Olympio, 1959.

BRIDGES, W. Um mundo sem empregos. São Paulo: Makron Books, 1995.

CHAUÍ, M. Escritos sobre a Universidade. São Paulo: Editora UNESP, 2001.

CHEVAlIER, J., GHEERBRANT, A. Dicionário de símbolos. Rio de Janeiro: José Olympio, 1991.

CLASTRES, P. Arqueologia da violência. São Paulo: Brasiliense, 1982.

NIETZSCHE, F. Kritische Studienausgabe. Munique: DTV/de Gruyter, 1988.

SILVA, F. L. A experiência universitária entre dois liberalismos. Tempo Social (São Paulo), v.11, n.1, p.1-47, maio 1999. 


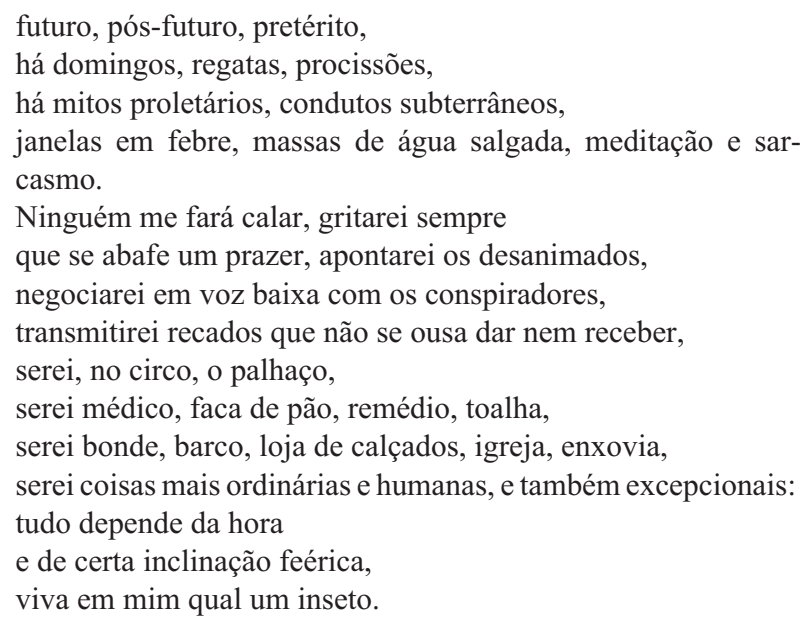

BRUNI, J. C. Guest speaker's address. Trans/Form/Ação (São Paulo), v.25, p.79-85, 2002.

- ABSTRACT: This is the text of the guest speaker's address given on the graduation ceremony of the 2001 class at the Faculdade de Filosofia e Ciencias da Universidade Estadual Paulista at Marilia/São Paulo. It consists in a briefreflection about the moment of graduation, the passage to professional life and the most serious problems of academic life today in Brazil.

- KEYWORDS: Graduation; passage rite; student; education; University; organization; institution.

\section{Referências bibliográficas}

ANDRADE, C. D. Poemas. Rio de Janeiro: José Olympio, 1959.

BRIDGES, W. Um mundo sem empregos. São Paulo: Makron Books, 1995.

CHAUÍ, M. Escritos sobre a Universidade. São Paulo: Editora UNESP, 2001.

CHEVAlIER, J., GHEERBRANT, A. Dicionário de símbolos. Rio de Janeiro: José Olympio, 1991.

CLASTRES, P. Arqueologia da violência. São Paulo: Brasiliense, 1982.

NIETZSCHE, F. Kritische Studienausgabe. Munique: DTV/de Gruyter, 1988.

SILVA, F. L. A experiência universitária entre dois liberalismos. Tempo Social (São Paulo), v.11, n.1, p.1-47, maio 1999. 